\title{
Climanosco Research Articles
}

Collection 3, Human responses to climate change

\section{Human reactions to climate change: a social psychological perspective}

By Rusi Jaspal and Brigitte Nerlich, 18 February 2022

\section{RESEARCH ARTICLE}

Climate change is a significant global challenge but also a controversial topic. In this article, we present an integrative theoretical framework and discuss the social psychological aspects of climate change, focusing on how it is communicated and understood, and how people respond to it. First, we focus on linguistic constructions of climate change and its mitigation measures, drawing on tenets of social representations theory. Second, we outline the individual and group levels of identity and their relevance to understanding how people respond to particular social representations of climate change and its mitigation measures. Third, through the lens of identity process theory, we discuss relevant climate change behaviours in terms of coping strategies which operate at individual, interpersonal and intergroup levels. We argue that social representations of climate change (and its mitigation strategies) must resonate among the general population; that they must not excessively challenge identity and wellbeing; and that people should be empowered to take action against climate change.

\section{Introduction}


Climate change remains a significant global challenge but it is also a controversial topic marred by political inertia, and conspiracy theories. In society, there is not yet complete consensus - at the political or public levels - about how it must be tackled or even about its very existence. Some governments deny or downplay the existence or magnitude of climate change and so do not regard climate change mitigation as a political priority. For a long time, climate change was seen by many as a 'distant' problem, both in terms of time and space, but more and more people are now alarmed about climate change and its impacts [M. Goldberg et al., 2020]. Scientists have generated robust climate models which provide reliable predictions about the impact of current environmental policies and behavioural trends on the climate, planet and, ultimately, humanity. However, while risk awareness has increased and behaviour is changing especially among young people, polarisation still impedes the implementation of individual and institutional mitigation measures [H. Chu and J.Z. Yang, 2018].

In our research [R. Jaspal and B. Nerlich, 2014; B. Nerlich and R. Jaspal, 2014; R. Jaspal et al., 2014; R. Jaspal et al., 2013; N. Koteyko et al., 2013], we have been focusing on another key dimension of climate science - namely, the social, psychological, political and linguistic factors that undoubtedly influence the relationship between risk awareness and behaviour change. In this article, we focus on how science communicators might communicate climate science and mitigation techniques more effectively and how policymakers might design policies and interventions that lead to more sustainable behaviour change to mitigate the impact of climate change.

\section{Representations of climate change}

Like any form of science, climate science is characterised by debate and discussion. The predictive nature of forecasting future climate scenarios is more an exercise in probabilities than in certainties. Yet, it is an important duty to communicate scientific climate change findings to policymakers and the public in order to encourage appropriate action to mitigate the risk of adversity. This means developing effective policies (e.g., plans to reduce carbon emissions) and behavioural changes in the general public (e.g., increased recycling and use of public transportation).

Social representations theory [S. Moscovici, 1988] from social psychology can help us understand how climate science is communicated and with what effects for public awareness and understanding. First, given that climate science is hardly an area in which most people have expertise, we tend to use familiar and culturally accessible phenomena in order to support what we say about climate change. This is referred to as anchoring. For instance, we may 'anchor' climate change to extreme weather events, a link that was once contested but no longer is [M. Reynolds, 2020]. Second, we often use particular visual and linguistic 'tools' to describe climate change, which make it more tangible for the audiences 
with whom we wish to communicate [B. Nerlich and R. Jaspal, 2014]. For instance, some commentators refer to a 'climate crisis' or 'climate emergency' (Oxford Dictionaries' word of the year 2019) rather than just 'climate change' or more neutral terms, which is a metaphor that constructs climate change as urgent, dangerous and pervasive. Together, anchoring and objectification give rise to what we might call social representations, that is, frameworks of meaning which tell us how we should think, feel and act in relation to climate change. Social representations of climate change that circulate in our society include (1) 'climate change is a largely human-induced environmental problem' and (2) 'climate change is a hoax created by climate scientists for financial gain'. Of course, there are many, many others. It is important to note that each of these social representations are broad frameworks which imply how people should think, feel and behave in relation to climate change.

\section{The 'status' of social representations}

Clearly, not all social representations enjoy the same status or level of endorsement in the general public. Some are accepted by almost everybody while others are recognised only by smaller groups of people. For instance, the representation of human-induced climate change is accepted by the majority of people in society and by many governments which have pledged to reduce carbon emissions, although they perhaps do not agree on how best to balance this environmental goal with economic aspirations.

By contrast, the representation of climate change as a financially motivated hoax appears to be confined to subsections of the population, such as some on the political right, conspiracy theorists, and industrialists. Other than their individual feasibility or believability, there is nothing inherent about these representations that render them more or less consensually acceptable - their level of endorsement will depend on who spreads them, how and where they are disseminated, and whether or not they are understood. Put simply, powerful, influential and trusted individuals are more likely to convince people to accept any given social representation, and they will be more successful in doing so if they can reach people through the mass media and in using anchoring and objectification strategically so that climate change can be understood as the propagator wishes it to be.

It is also worth noting that, although social representations may originate in a particular context (such as the print media), they are often taken up, elaborated and challenged in other contexts (most notably, on social media). This provides a good rationale for analysing social representations of climate change in any context in which communication about this scientific issue occurs. When a social representation is (re)produced in several contexts, it is more likely to become part of human consciousness regarding climate change, regardless of whether or not it is actually accepted by the people exposed to it. From a methodological perspective, it is noteworthy that the most comprehensive analyses of public understanding 
of climate change will involve an exploration of social representations in various contexts, such as political rhetoric, the print media, social media and so on. Social media platforms (such as Twitter) are an especially important forum to analyse as social representations are constantly introduced, elaborated and challenged - at a much higher velocity and by more groups and individuals than many other forums. They should constitute one of our research foci to examine public understanding of climate change.

\section{Human identity}

Researchers have now recognised the importance of identity in human responses to climate change at both the individual and group level [K.S. Fielding and M.J. Hornsey, 2016]. How an individual reacts to (the threat of) climate change depends on who they are, and who they are is shaped by the people close to them. If social representations of climate change resonate with the norms, goals and aspirations of key social groups, they will probably be more effective in shaping cognition, emotion and behaviour in relation to climate change.

On the other hand, human responses to climate change operate at an individual psychological level in that, in some contexts, human beings think principally in terms of their individual identity, rather than their group identity. In our research, we have drawn on aspects of identity process theory [G.M. Breakwell, 2001; G.M. Breakwell, 2015; R. Jaspal and G.M. Breakwell, 2014] to understand how individuals may respond to social representations of climate change.

The theory postulates that identity is the product of the two identity processes: assimilation-accommodation and evaluation. The assimilation-accommodation process refers to how people absorb and adopt new information (e.g. social representation of climate change as human-induced) into their identity and evaluation refers to the process of attaching meaning and value to it (e.g. this representation is frightening). The two processes are in turn guided by the identity principles which include self-esteem, positive distinctiveness, self-efficacy, and continuity. When the identity processes clash with the identity principles, identity is said to be threatened and this, in turn, has repercussions for psychological wellbeing. In other words, it does not feel good. For instance, the social representation of climate change as human-induced implies that human beings have a role to play in mitigating it through behaviour change, such as by using public transport more. This may challenge the individual's continuity because the required behaviour change may disrupt the thread between past, present and future [R. Jaspal, 2014]. Furthermore, the meanings attached to the undesirable behaviour (i.e. using one's own car) may be very positive and one's own car may be central to one's self-esteem. In other words, one may feel best about oneself when one is behind the wheel and to change this behaviour may inhibit these positive feelings. To use one's car less might undermine self-esteem. 
In short, some social representations of climate change may lead to identity threat among the individuals whom we seek to engage when we communicate with them, because they potentially deprive them of self-esteem, continuity and so on. This also applies to large institutions, like fossil fuel companies or political parties. Conversely, other competing social representations may be available in one's social context which enhance identity, that is, which provide continued feelings of self-esteem, continuity and so on. It is this selection of competing social representations that renders climate change so contentious a topic. Yet, the key point is that people appear to cling to those social representations that enhance identity and to reject those that threaten it. After all, we are psychologically motivated to achieve psychological wellbeing.

\section{Coping with change}

In response to identity threat, individuals engage in coping strategies. These are essentially patterns of behaviour which enable the individual to reduce, or preferably eradicate, identity threat. Some are adaptive (challenging in the short term but effective and sustainable in the long term), and others maladaptive ('quick-fix' solutions with limited effectiveness and sustainability in the long term). Identity process theory describes three levels of coping: (1) intrapsychic, (2) interpersonal and (3) intergroup strategies. In response to threatening social representations of climate change (whatever they may be), individuals will attempt to cope.

\section{Intrapsychic coping strategies}

Intrapsychic strategies operate at the level of individual cognition and include denial, reconceptualisation and anticipatory restructuring. For instance, in response to the potentially threatening social representation of human-induced climate change, some individuals will deny the social representation and its significance, thereby removing the need for action. Some will reconceptualise the threat itself (i.e. climate change), perhaps by construing climate change as an 'inevitable' chapter in the life course of the planet. This too avoids the need for action. By contrast, anticipatory restructuring involves acceptance of the social representation of human-induced climate change but re-structuring one's identity so that one can take actions to mitigate its risk. For instance, one may begin to view oneself as a 'walker' and, thus, begin to walk to work, rather than use one's car as frequently. This essentially enables identity to change so that one can take positive action in response to the hazard (i.e. climate change).

\section{Interpersonal and intergroup strategies}

Interpersonal and intergroup strategies involve changing the patterns of one's relationships with other individuals and groups to limit identity threat. For instance, individuals may engage in group mobilisation to advocate their particular social representation of climate 
change. They mobilise other people who share a belief in the same social representation which in turn enables them to advocate it and influence others more effectively. This can limit identity threat in several ways. For instance, a pressure group formed to reject the social representation of human-induced climate change essentially removes the need for behaviour change (e.g. using public transport more, divestment from fossil fuels and so on) which may originally have threatened identity. People tend to seek consensus and, thus, being surrounded by like-minded others who share one's belief in a particular social representation of climate change can be a positive experience.

\section{Conclusions}

Alongside the scientific study of the climate, we need the scientific study of social representations, identity and behaviour. This is vitally important in the promotion of awareness, understanding and behaviour change that will limit the harmful effects of climate change. In this article, we have described a broad theoretical framework - drawing on social representations theory and identity process theory - within which human reactions to climate change can be understood.

Put simply, if we wish to promote effective, enduring and sustainable change in the context of climate change, we must ensure that social representations of climate change (and its mitigation strategies) resonate among the diverse individuals and groups we seek to engage; that those representations are not construed as too threatening; that, if they do threaten identity, there are clear, discernible pathways towards resolving the threat; and that we promote coping strategies that are effective and sustainable. The significance of these issues is clearly observable in the context of the COVID-19 pandemic where people have had to grapple with uncertainty, changing rules and instability. For some, the threatening nature of the pandemic and how it has been handled in some contexts has led them to disengage from preventive activity.

In his research into identity and behaviour change in the context of health, [R. Jaspal, 2018] has argued that practitioners (which can be defined broadly in terms of 'experts', educators and policymakers) have an important role to play in determining the coping strategies that people can adopt and to provide the contexts in which they can adopt them. We all have a responsibility to promote the adoption of those strategies that will empower people to feel that they can do their bit. It is only then that they will be able and competent to engage with perhaps one of the greatest societal challenges of all time - climate change.

\section{Bibliography}

- G.M. Breakwell: Social representational constraints upon identity processes, in: 
Representations of the Social : Bridging Theoretical Traditions, K. Deaux and G. Philogene (Eds.). Oxford: Wiley, 271-284, 2001.

- G.M. Breakwell: Coping with Threatened Identities. London: Routledge, 2015.

- H. Chu and J.Z. Yang: Taking climate change here and now - mitigating ideological polarization with psychological distance, Global Environmental Change, vol. 53, 174-181, https://doi.org/10.1016/j.gloenvcha.2018.09.013, 2018.

- K.S. Fielding and M.J. Hornsey: A social identity analysis of climate change and environmental attitudes and behaviors: Insights and opportunities, Frontiers in Psychology, vol. 7(121), https://doi.org/10.3389/fpsyg.2016.00121, 2016.

- M. Goldberg, A. Gustafson, S. Rosenthal, J. Kotcher, E. Maibach and A. Leiserowitz: For the first time, the alarmed are now the largest of global warming's six Americas, Climate Note, Yale University and George Mason University. New Haven, CT: Yale Program on Climate Change Communication., 2020. Retrieved from https://climatecommunication.yale.edu/publications/for-the-first-time-the-alarmed-are -now-the-largest-of-global-warmings-six-americas/.

- R. Jaspal: Identity threat and resistance to change: Evidence and implications from transport-related behavior, in: Identity Process Theory: Identity, Social Action and Social Change, R. Jaspal and G.M. Breakwell (Eds.). Cambridge: Cambridge University Press, 2014.

- R. Jaspal: Enhancing Sexual Health, Self-Identity and Wellbeing among Men Who Have Sex With Men: A Guide for Practitioners. London: Jessica Kingsley Publishers, 2018.

- R. Jaspal and G.M. Breakwell: Identity Process Theory: Identity, Social Action and Social Change, R. Jaspal and G.M. Breakwell (Eds.). Cambridge: Cambridge University Press, 2014.

- R. Jaspal and B. Nerlich: When climate science became climate politics: British media representations of climate change in 1988, Public Understanding of Science, vol. 23(2), 122-41, https://doi.org/10.1177/0963662512440219, 2014.

- R. Jaspal, B. Nerlich and M. Cinnirella: Human responses to climate change: Social representation, identity and socio-psychological action, Environmental Communication: A Journal of Nature and Culture, vol. 8(1), 110-130, https://doi.org/10.1080/17524032.2013.846270, 2014.

- R. Jaspal, B. Nerlich and N. Koteyko: Contesting science by appealing to its norms: Readers discuss climate science in The Daily Mail, Science Communication, vol. 35(3), 383-410, https://doi.org/10.1177/1075547012459274, 2013.

- N. Koteyko, R. Jaspal and B. Nerlich: Climate change and Climategate in online reader comments: A mixed methods study, The Geographical Journal, vol. 179(1), 74-86, https://doi.org/10.2307/23360887, 2013.

- S. Moscovici: Notes towards a description of Social Representations, European Journal of Social Psychology, vol. 18, 211-250, https://doi.org/ 10.1002/ejsp.2420180303, 1988. 
- B. Nerlich and R. Jaspal: Images of extreme weather: Symbolising human responses to climate change, Science as Culture, vol. 23(2), 253-76, https://doi.org/10.1080/09505431.2013.846311, 2014.

- M. Reynolds (03 2020): Scientists are finally linking extreme weather to climate change, Wired. Retrieved from https://www.wired.co.uk/article/climate-change-weather-attribution.

\section{Article information}

Cite as Rusi Jaspal and Brigitte Nerlich, Human reactions to climate change: a social psychological perspective, Climanosco Research Articles 3, 18 Feb 2022, https://doi.org/10.37207/CRA.3.2

ISSN 2673-1568

DOI https://doi.org/10.37207/CRA.3.2

Retrieved 18 Feb 2022

Version 1

In collection 3, Human responses to climate change

\section{Authors}

Rusi Jaspal, Vice-Chancellor's Office, University of Brighton, Brighton BN2 4GJ, United Kingdom

Brigitte Nerlich, School of Sociology and Social Policy, Institute for Science and Society, University of Nottingham, UK

\section{Categories}

Adaptation, Climate of the future, Climate of the past, Climate of the present, Health, Human activities, Impacts, Law \& policy, Risks, Vulnerability, Global

\section{Metadata}

Date of final publication 18 February 2022

Type of article: Focus article; Multiple source article

Permanent url address:

https://www.climanosco.org/published_article/human-reactions-to-climate-change-a-soci al-psychological-perspective/ 